\title{
SUGGESTED TEST SEQUENCE AMENDMENTS OF THE CURRENT ECSS E-ST-20-08C STANDARD FOR BARE SOLAR CELLS QUALIFICATION
}

\author{
Blanco, G. ${ }^{(1)}$, Jüngst, G. ${ }^{(2)}$, Grás, A. ${ }^{(1)}$ \\ (1) INTA-SPASOLAB, Careterra de Ajalvir km. 4, 28850 Torrejón de Ardoz, Spain, Email: blancomg@inta.es, \\ grassa@inta.es \\ (2) ISDEFE Consulting, C/ Beatriz de Bobadilla 3, 28040 Madrid, Spain,Email: jungstg.pers_externo@inta.es
}

\begin{abstract}
INTA-SPASOLAB as independent testing facility for more than 25 years has an extensive expertise in the certification and qualification of photovoltaic devices for space applications. Recently INTA-SPASOLAB has participated in the qualification of the latest technology upgrade of lattice-matched III-V GaInP/GaInAs/Ge triple-junction (TJ) bare solar cells manufactured by AZUR SPACE Solar Power GmbH (Germany). This participation has consisted of carrying out test sequences of subgroup B, Beginning of Life (BOL) performance, $\mathrm{C} 1$ (Electron Irradiation) and $\mathrm{P}$ (Proton Irradiation) according to the current ECSS E-ST$20 \neg 08 \mathrm{C}$, Rev. 1 reference standard.

At these subgroup qualifications, some performance tests, in particular spectral response and electric performance tests, have been agreed to be either modified in the test sequence order or added, in order to understand better the evolution of the electrical cell parameter results.

In this work, test sequence variations and obtained results on those subgroups $\mathrm{B}, \mathrm{C} 1$ and $\mathrm{P}$, are presented. The gained experience at this qualification and other previous work about solar cell characterization is used to suggest amendments.
\end{abstract}

\section{INTRODUCTION}

Solar cells have been used for electrical power generation since the Vanguard 1 satellite mission. One of the main problems encountered on their mission operation is their vulnerability to the harmful environmental space conditions, and in consequence a lost in power generation.

For this and other reasons of space product assurance, the European Space Agency (ESA) and European industry associations established so called European Cooperation for Space Standardisation (ECSS) qualification standards. In particular, for photovoltaic solar cell assemblies the document ECSS-E-ST-20-08C, Rev 1 is the reference standard [1].

\section{TEST SECUENCE DESCRIPTION}

All test measurements of this qualification have been carried out by following accordingly the test sequence and requirements of the ECSS-E-ST-20-08C standard. In addition, following test deviations have been agreed, as highlighted in Table 1:

\begin{tabular}{|c|c|c|}
\hline $\begin{array}{c}\text { Subgroup B } \\
\text { (BOL Performance) }\end{array}$ & $\begin{array}{l}\text { Subgroup C1 } \\
\text { (e- Irradiation) }\end{array}$ & $\begin{array}{c}\text { Subgroup P } \\
(\mathrm{p}+\text { Irradiation })\end{array}$ \\
\hline $01 \mathrm{VI}$ & $01 \mathrm{VI}$ & $01 \mathrm{VI}$ \\
\hline $02 \mathrm{DW}$ & $02 \mathrm{DW}$ & $02 \mathrm{DW}$ \\
\hline 04FT & 03EP & 03EP \\
\hline 05EP & 04DC & 04DC \\
\hline $06 \mathrm{DC}$ & $05 \mathrm{SR}^{[* *]}$ & $05 \mathrm{SR}^{[* *]}$ \\
\hline $07 \mathrm{PH}$ & $06 \mathrm{EI}$ & 06PI \\
\hline $07 \mathrm{EP}^{[*]}$ & $07 \mathrm{VI}$ & $07 \mathrm{VI}$ \\
\hline 07TA & $08 \mathrm{EP}^{[*]}$ & $08 \mathrm{EP}^{[*]}$ \\
\hline 08EP & $08 \mathrm{PH}$ & $08 \mathrm{PH}$ \\
\hline 09DC & $08 \mathrm{EP}^{[*]}$ & $08 \mathrm{EP}^{[*]}$ \\
\hline 10TC\&TB & 08TA & 08TA \\
\hline $110 P$ & $08 \mathrm{EP}^{\left[{ }^{*}\right]}$ & $08 \mathrm{EP}^{[*]}$ \\
\hline $12 \mathrm{RB}$ & 09EP & 09EP \\
\hline 13EP & $10 \mathrm{DC}$ & $10 \mathrm{DC}$ \\
\hline $14 \mathrm{VI}$ & $11 \mathrm{TC} \& \mathrm{~TB}$ & $11 \mathrm{TC} \& \mathrm{~TB}$ \\
\hline \multirow[t]{5}{*}{$15 \mathrm{SR}^{/ \ldots+* * /}$} & 12RB & $12 \mathrm{SR}^{[* * *]}$ \\
\hline & 13EP & $13 \mathrm{VI}$ \\
\hline & $14 \mathrm{SR}^{\Omega^{* * * *} J}$ & $14 \mathrm{SR}^{/ \cdots \cdots /}$ \\
\hline & $15 \mathrm{VI}$ & \\
\hline & $16 \mathrm{SR}^{/ \ldots \ldots * \pi}$ & \\
\hline \multicolumn{3}{|c|}{$\begin{array}{l}{ }^{[*]} \text { Additional EP step included } \\
{ }^{[* *]} \text { SR step moved before 03EP }\end{array}$} \\
\hline \multicolumn{3}{|c|}{${ }^{\left.I^{* * *}\right]}$ SR step moved before 09EP } \\
\hline
\end{tabular}

Table 1. Subgroups B, C1 and P Qualification Test Plan for Bare Solar Cells, plus agreed modifications (marked in colour) according to ECSS-E-ST-20-08C, Rev 1.

(1) One additional electric performance (EP) test between photon irradiation $(\mathrm{PH})$ and thermal annealing (TA) and three additional electric performance (EP) tests, first EP before $\mathrm{PH}$ and second $\mathrm{EP}$ after $\mathrm{PH}$ and before TA, were included in subgroups $\mathrm{B}, \mathrm{C} 1$ and $\mathrm{P}$, respectively, in order to determine separately possible effects of photon irradiation and thermal annealing on electrical cell performance.

(2) Spectral response measurements (SR) planned at step 05 have been anticipated before test step $03 \mathrm{EP}$ in both subgroups, $\mathrm{C} 1$ and $\mathrm{P}$, respectively, so that electrical cell performance of beginning of life (BOL) cells could be determined more accurately applying spectral mismatch factor correction before the next electron or proton irradiation test step.

(3) $\quad \mathrm{SR}$ measurements at lowest $\left(1175^{\circ} \mathrm{C}\right)$ and highest $\left(+140^{\circ} \mathrm{C}\right)$ cell temperature have been added as final test in subgroup $\mathrm{B}, \mathrm{C} 1$ and $\mathrm{P}$, respectively with two 
main objectives. Firstly, to determine possible temperature dependent spectral response degradation of EOL cells compared to those results at $28^{\circ} \mathrm{C}$ (this is not reported in this paper). Secondly, to compute spectral mismatch correction factors at these two temperatures and to determine potentially the impact on temperature coefficient (TC) results of electrical cell parameters.

In this work the results of these agreed deviations (1) to (3) are presented. Eventually, it is suggested that at test sequence of subgroup $\mathrm{B}, \mathrm{C} 1$ and $\mathrm{P}$ some EP and SR testing steps might be added.

\section{RESULTS}

\subsection{Electrical cell performance stability after photon irradiation and thermal annealing}

According to the applied ECSS standard, the stability of the electric solar cell performance under equivalent light and temperature of 1 solar constant (s.c.) AM0 conditions shall be verified by the two-step test, photon irradiation $(\mathrm{PH})$ and subsequent thermal annealing (TA), which is to be performed at BOL, after the Electron Irradiation and after the Proton Irradiation test step, respectively. For a better analysis of the relative changes of electrical cell parameters before and after the $\mathrm{PH}$ or TA test, additional electrical performance measurements have been included in between the $\mathrm{PH}$ and TA test step. The obtained changes are highlighted in Figure 1 for the selected parameters short circuit current (Isc), maximum power (Pmax) and open circuit voltage (Voc). For non-irradiated BOL cells solar cell performance has been within determined measurement uncertainty. By doing so, this performance has been considered to be stable. A pass-fail criterion of this verification item is not written explicitly in the ECSS standard. Concerning the irradiated cells, short circuit current retained its value within the $1 \%$ measurement uncertainty whose contribution is made up of, while the after EI or PI decreased Pmax and Voc results recovered. At the $1 \mathrm{MeV}$ electrons per $\mathrm{cm} 2$ irradiated cells this recovery was by tendency increasing continuously from lowest to highest fluence. In particular, from the $5 \mathrm{E}+14$ to the $1 \mathrm{E}+15$ fluence, the recovery contribution of Pmax might be addressed to thermal annealing, but, since this increase stays within a $1 \%$ standard measurement uncertainty, this is not sufficient evidence. Hence, taking into account the applied fluences at EI and PI testing, it is considered that there is no need to add any EP tests related to this $\mathrm{PH}$ plus TA test, respectively.

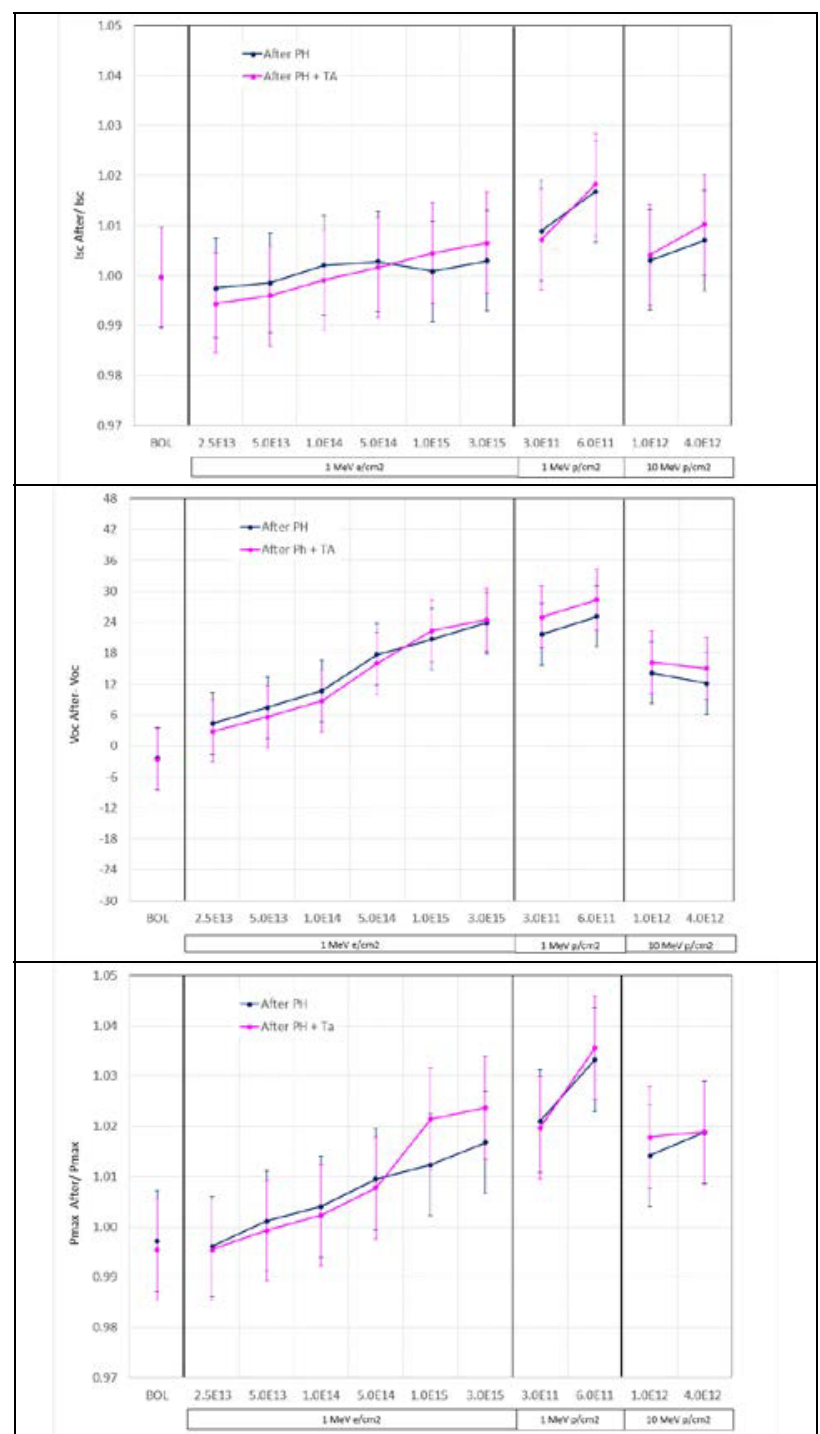

Figure 1: Obtained relative changes of Isc, Voc and Pmax of BOL, electron or proton irradiated cells after photon irradiation (PH) and thermal annealing (TA) test steps, respectively.

\subsection{Accuracy benefits from Spectral Response Measurements before Electrical Performance Characterization}

At the electric performance (EP) tests first 1 s.c. AM0 effective irradiance conditions on the solar simulator are adjusted, as described in [2], by using single component reference (SCRC) cells calibrated in Isc with regards to the WMO reference spectrum, spatial irradiance uniformity corrections, if applicable, and spectral mismatch correction factors $\mathrm{Mj}$ at each subcell $\mathrm{j}$ of the triple junction (TJ) test cell. By applying these $\mathrm{Mj}$ factors, this adjustment can be set more accurately with the benefit of more accurate and reliable electrical cell parameter results.

At the computation of $\mathrm{Mj}$ according to equation (1), the 
spectral response $S R{ }_{\text {test }}$ of each TJ cell's subcell j need to be determined previously before the EP test:

$$
M_{j}\left(E_{k}\right)=\frac{\int S R_{\text {test }}^{j} E_{A M 0} d \lambda \cdot \int S R_{r e f}^{j} E_{k} d \lambda}{\int S R_{\text {test }}^{j} E_{k} d \lambda \cdot \int S R_{r e f}^{j} E_{A M 0} d \lambda}
$$

where $S R{ }^{j}$ is the spectral response of the SCRC cell, $E_{A M 0}$ the spectral distribution of the AM0 reference spectrum WMO, while $E_{S I M}$ corresponds to the spectral irradiance of the solar simulator's light sources measured by a calibrated spectroradiometer.

Due to the fact that in the current ECSS the SR test was either not included in the test sequence of subgroup B, or in subgroup $\mathrm{C} 1$ and $\mathrm{P}$ was chronologically situated after the 03-EP step and as well after the 09-EP step, which is the step after electron or proton irradiation, SR tests have been performed before the aforementioned EP tests in this qualification test.

In this section spectral mismatch factor results $\mathrm{Mj}$ at respective testing steps are presented except those $\mathrm{Mj}$ of the Germanium (Ge) bottom subcell. Due to the excessive short circuit current generation of the $\mathrm{Ge}$ subcell of the TJ test cells compared to the GaInP and InGaAs subcell currents at EP tests, $\mathrm{Mj}$ correction of this subcell was not relevant.

It is to be pointed out that the employed SCRC cells were $3 \mathrm{G} 30$ isotype component cells of the triple junction test cells to be qualified with same cell dimension and geometry.

Regarding to the BOL EP tests (05-EP of subgroup B, and 03-EP of $\mathrm{C} 1$ and $\mathrm{P}$ ), $\mathrm{Mj}$ results were $0.994+/-0.001$ for the GaInP (top) subcells, while $1.001+/-0.001$ for the InGaAs (middle) subcells, respectively.

This means, that, without applying spectral mismatch correction at these EP tests, the BOL TJ testing cells, whose current limiting subcell is precisely the GaInP subcell, are illuminated by a $0.6 \%$ less light intensity than required. As consequence, the measurement uncertainty $\mathrm{u}$ (Ycell) of electrical cell parameter Ycell increases, especially in Isc, Impp and Pmax. Apart from the $1 \%$ calibration standard uncertainty of the SCRC, the $u(Y$ cell) increases by this additional error. The amount of increase depends on the sensitivity coefficient $\delta Y$ cell $/ \delta \mathrm{Mj}$, which depends on the cell type and can be determined at Spasolab [3] by spectrometric characterization [4].

Regarding to the EP tests at $28^{\circ} \mathrm{C}$ after electron or proton irradiation (09-EP and 13-EP in subgroup $\mathrm{C} 1$ and 09-EP in subgroup $\mathrm{P}$ ), the spectral mismatch factor changes with respect to its $\mathrm{BOL}$ value have been determined for the respective GaInP and InGaAs subcell of the End-Of-Life (EOL) testing cells after electron or proton irradiation step at different fluences.

As highlighted in Figure 2, spectral mismatch factors of the BOL results changed for the InGaAs subcell slightly increasing, but by tendency towards the maximum fluences, being $0.3 \%$ the maximum deviation at $3 \mathrm{E}+15$
$1 \mathrm{MeV}$ electron fluence per $\mathrm{cm}^{2}$ in this qualification test.

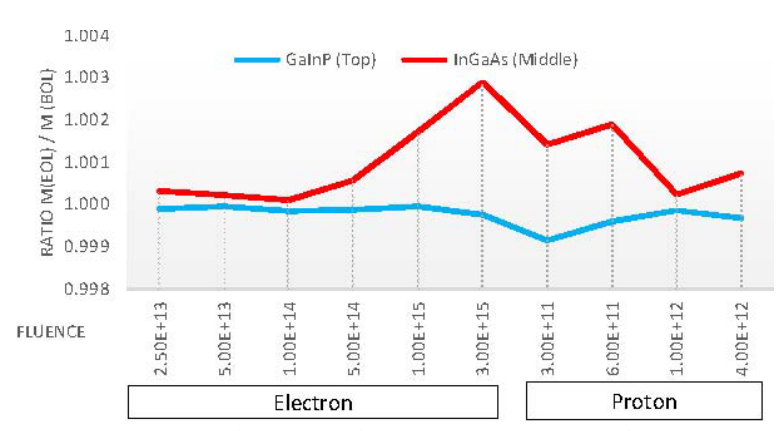

Figure 2: Relative change of spectral mismatch correction factor of EOL testing cells after electron or proton irradiation at different fluences with respect to its BOL value.

\subsection{Spectral Response Measurements at extreme temperatures for temperature coefficient analysis}

Spectral Response measurements of the EOL TJ testing cells of subgroup $\mathrm{C} 1$ and $\mathrm{P}$ at the extreme cell temperatures $-175^{\circ} \mathrm{C}$ and $+140^{\circ} \mathrm{C}$ have been included as additional step, 16-SR, as depicted in Table 1, at the test sequence end. The objectives of these SR tests have been twofold:

(i) Firstly, to determine the change of spectral mismatch correction factors $\mathrm{M}_{\mathrm{j}}(\mathrm{T})$ at these extreme temperatures with regards to $28^{\circ} \mathrm{C}$, and

(ii) Secondly, at test step 11-TC, to assess the impact of the produced error on electrical cell parameters Ycell at extreme temperatures when not using at the temperature coefficient (TC) measurements of Ycell, the temperature corresponding correction factor $\mathrm{M}_{\mathrm{j}}$ (T), but $\mathrm{Mj}\left(\mathrm{T}=28^{\circ} \mathrm{C}\right)$ at $28^{\circ} \mathrm{C}$ instead.

The results of the first objective are highlighted in next two figures, Figure 3 at $-175^{\circ} \mathrm{C}$ and Figure 4 at $+140^{\circ} \mathrm{C}$.

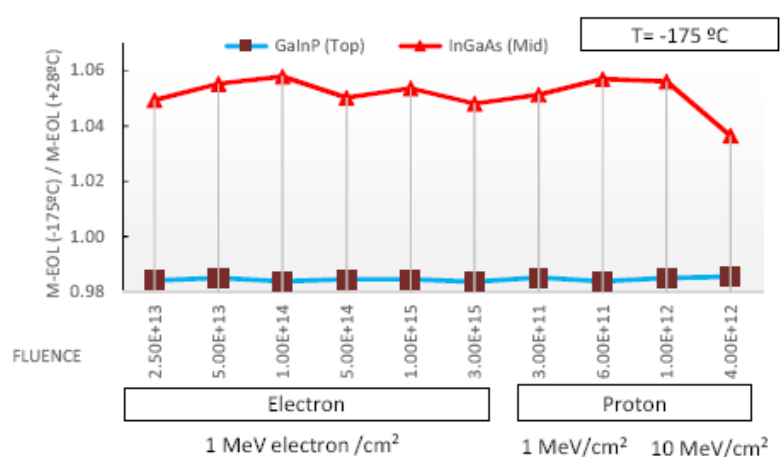

Figure 3: Relative change of spectral mismatch correction factor $\mathrm{M}$ at cell temperature of $-175^{\circ} \mathrm{C}$ with respect value $\mathrm{M}$ at $+28^{\circ} \mathrm{C}$ for $\mathrm{EOL}$ testing cells after electron or proton irradiation at different fluences. 


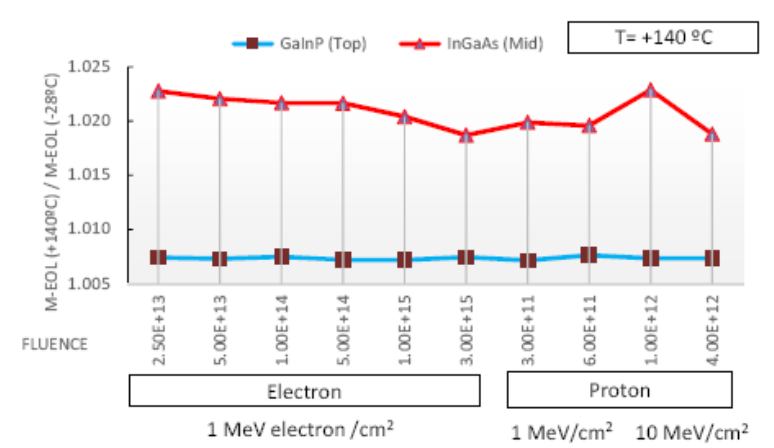

Figure 4: Relative change of spectral mismatch correction factor $\mathrm{M}$ at cell temperature of $+140^{\circ} \mathrm{C}$ with respect value $\mathrm{M}$ at $+28^{\circ} \mathrm{C}$ for EOL testing cells after electron or proton irradiation at different fluences.

While the relative changes of $\mathrm{Mj}$ ( $\mathrm{T}$ ) of the GaInP subcell at $-175^{\circ} \mathrm{C}$ were constantly at $0.984+/-0.001$, these relative changes turned to $1.007+/-0.001$ at $+140^{\circ} \mathrm{C}$. In contrast, the relative changes $\mathrm{Mj}(\mathrm{T})$ of the InGaAs subcell have been superior to unity at both extreme temperatures, 1.05 at $-175^{\circ} \mathrm{C}$ and 1.02 at $+140^{\circ} \mathrm{C}$, respectively, and varied in a broader value range $+/-0.01$. It is to be pointed out that these obtained mismatch results cannot be taken as general results, since these are not independent on the utilised solar simulator.

Regarding to the second objective, the error of applied $M_{j}$ (T) affect to Ycell results depending on which the current limiting subcell at a certain temperature is, either the GaInP or to the InGaAs subcell in the tested TJ cells. While this effect can be determined directly in case of Isc, at other cell parameters, e.g. Pmax, the spectrometric characterization tool, described in [4], needs to be used.

In Figure 5 the Isc case is illustrated on the example of an irradiated TJ testing cell, whose current limiting subcell has been the InGaAs subcell. Due to the relative change of the mismatch correction factor at $+140^{\circ} \mathrm{C}$, by 1.02 , the resulting short circuit current at $+140^{\circ} \mathrm{C}$ has been overestimated by $2 \%$. In change, at lowest temperature of $-175^{\circ} \mathrm{C}$ the overestimation of shortcircuit current has been major, around 5\% according to the error change of 1.05 .

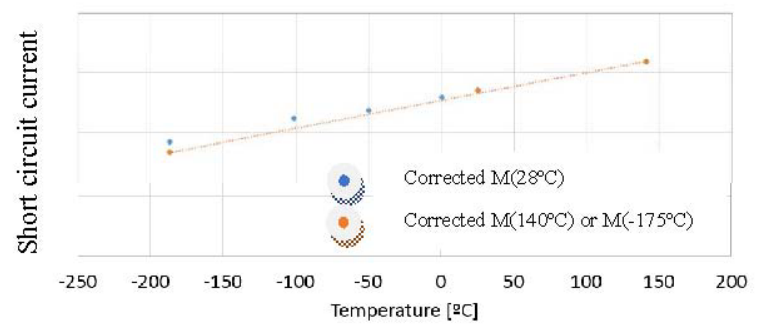

Figure 5: Isc results as effect of applied or not applied spectral mismatch correction at an irradiated TJ test cell of this qualification.

\section{CONCLUSIONS}

In the qualification of subgroup $\mathrm{B}, \mathrm{C} 1$ and $\mathrm{P}$ of bare $\mathrm{TJ}$ solar cells, the agreed test variations on test sequence according to the ECSS-E-ST-20-08C, Rev 1 standard [1] and their obtained results on electrical cell performance have been presented in this work.

Related to the test of photon irradiation (PH) and thermal annealing (TA) to verify the solar cell performance stability, it is shown that electric cell parameter results after respective $\mathrm{PH}$ and TA step have not varied more than determined measurement uncertainty for the particular TJ test cells. As stability criterion the obtained measurement uncertainty has been utilised, although it is suggested to have an explicit criterion available in this ECSS standard. Concerning the electrical parameters (EP) characterization, before and after each irradiation, I-V curves were recorded for all cells to follow the evolution of the tested parameters. This method requires the characterization and accurate adjustment of the solar simulator. For doing this, it is suggested to perform spectral response measurements of the tested cells at different testing temperatures previous to the EP characterization at the same temperatures. This method allows achieving a more accurate match to the AM0 reference spectrum and controlling the uncertainty of the electrical cell parameters. It is to be pointed out that spectral mismatch corrections results are typical of each solar simulator. Hence, these corrections could not be used as a general case for all the used set up.

\section{REFERENCES}

[1] ECSS-E-ST-20-08C, Rev 1 (2012). Space Engineering Photovoltaic assemblies and components. ECSS Secretariat, ESA-ESTEC Requirements \& Standards Division, Noordwijk, The Netherlands.

[2] A. Grás, et al., Analysis for Multi-Junction Solar Cell Measurements at Spasolab, Proc. '6th European Space Power Conference', Porto, Portugal, 577-580, 610 May 2003.

[3] G. Jüngst, A. Grás, et. al. "Measurement uncertainty for electric performance calibration of triple junction solar cells at Spasolab", $29^{\text {th }}$ PVSEC conference, Paris (France), 2013.

[4] C. Baur, A. Bett, "Measurement uncertainties of the calibration of multi-junction solar cells", IEEE proceedings of $31^{\text {st }}$ IEEE PVSC, Florida, 2005. 